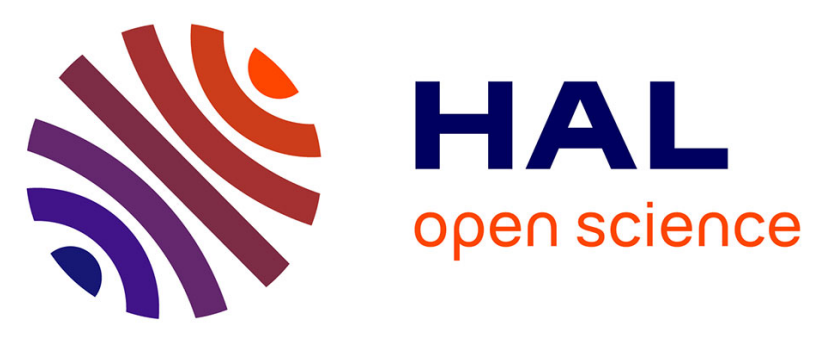

\title{
Ascorbic acid drives the differentiation of mesoderm-derived embryonic stem cells. Involvement of p38 MAPK/CREB and SVCT2 transporter
}

Fryad Rahman, Benoit Bordignon, Raphael Culerrier, Franck Peiretti, Salvatore Spicuglia, Malek Djabali, Jean-Francois Landrier, Michel Fontes

\section{To cite this version:}

Fryad Rahman, Benoit Bordignon, Raphael Culerrier, Franck Peiretti, Salvatore Spicuglia, et al.. Ascorbic acid drives the differentiation of mesoderm-derived embryonic stem cells. Involvement of p38 MAPK/CREB and SVCT2 transporter. Molecular Nutrition and Food Research, 2017, 61 (5), pp.1600506. 10.1002/mnfr.201600506 . hal-01798873

\section{HAL Id: hal-01798873 \\ https://hal-amu.archives-ouvertes.fr/hal-01798873}

Submitted on 24 May 2018

HAL is a multi-disciplinary open access archive for the deposit and dissemination of scientific research documents, whether they are published or not. The documents may come from teaching and research institutions in France or abroad, or from public or private research centers.
L'archive ouverte pluridisciplinaire HAL, est destinée au dépôt et à la diffusion de documents scientifiques de niveau recherche, publiés ou non, émanant des établissements d'enseignement et de recherche français ou étrangers, des laboratoires publics ou privés. 


\title{
Ascorbic acid drives the differentiation of mesoderm-derived embryonic stem cells. Involvement of p38 MAPK/CREB and SVCT2 transporter
}

\author{
Fryad Rahman ${ }^{1,4}$, Benoit Bordignon ${ }^{1}$, Raphael Culerrier ${ }^{2}$, Franck Peiretti ${ }^{1}$, \\ Salvatore Spicuglia ${ }^{3}$, Malek Djabali ${ }^{2}$, Jean François Landrier ${ }^{1 *}$ and Michel Fontes ${ }^{1 *}$ \\ ${ }^{1}$ NORT. UMR INSERM 1062, INRA 1260, Aix-Marseille University, Marseille Cedex 5, France \\ ${ }^{2}$ CNRS-UMR 5088/University of Toulouse-3, Université-Paul-Sabatier, Toulouse Cedex, France \\ ${ }^{3}$ TAGC. INSERM U1090, Aix-Marseille University, Marseille Cedex 09, France \\ ${ }^{4}$ Department of Biology, Faculty of Science, University of Sulaimani, Sulaimani, Kurdistan Region, Iraq
}

Scope: Here we tested the hypothesis that ascorbic acid (AA) is a signaling molecule acting on stem cells via the differentiation of mesoderm derivatives, including myocytes, osteocytes, and adipocytes.

Material and methods: Investigations used a murine embryonic stem cell line CGR8 able to differentiate into different cell types and treated or not with ascorbic acid. Differentiation was tracked mainly through cellular anatomy (including presence of beating cardiomyocytes) and expression of specific markers.

Conclusion: The study demonstrated that AA drives mesoderm-derived stem cell differentiation toward myogenesis and osteogenesis and also inhibits adipogenesis. Further experiments found that AA competes with retinoic acid (RA) to drive cell differentiation in a dose-dependent manner: AA inhibited neurogenic differentiation and stimulated myogenesis whereas RA did the reverse. The AA-dependent differentiation of embryonic stem cells was shown to involve a p38 MAPK/CREB pathway, probably stimulated by cAMP via adenylate cyclases. In addition, SVCT2, the intracellular transporter of AA, acted as a receptor. Finally, we showed that activation/repression of specific differentiation markers is associated with epigenetic changes in their associated promoters. We discuss the impact of these findings in terms of obesity and aging.

\section{Keywords:}

Ascorbic acid / Differentiation / Mesoderm derivatives / Obesity / Overweight

Additional supporting information may be found in the online version of this article at the publisher's web-site

\section{Introduction}

L-Ascorbic acid (AA), often referred to as Vitamin C, is essential for life in humans where its antioxidant properties protect cells against oxidative stress [1]. However, as humans are unable to synthesize AA, due to a mutation in the gene of L-gulonolactone oxidase (GULO), it needs to be provided through diet [2].

The metabolic and biochemical properties of AA have been extensively documented and are mostly associated with the chemical nature of the molecule and its antioxidant mechanisms. However, research has only recently started to see AA

Correspondence: Michel Fontes

E-mail: michel.fontes@univ-amu.fr
Received: July 9, 2016

Revised: October 28, 2016

Accepted: November 3, 2016 as a potential signaling molecule, in much the same way as retinoic acid (the active molecule of vitamin A).

In 2004, we demonstrated in a mouse model of CharcotMarie-Tooth type 1A disease (an inherited peripheral neuropathy) that high-dose AA treatment at least partly corrects the phenotype of transgenic mice [3]. We also found that the intracellular cAMP pool decreases with increasing concentrations of AA. This inhibition is specific to AA and is not shared by other antioxidants [4]. Classical enzymatic experiments showed that AA is a competitive inhibitor of adenylate cyclase [5]. AA thus downregulates the expression of genes that are under the control of the cAMP-dependent pathway. We later demonstrated that AA represses cell proliferation in

\footnotetext{
*Both authors contributed equally to this work.
} 
vitro as well as in vivo [6]. Taken together, these studies suggested that AA could be considered an important player in cell differentiation through a new function as global regulator of the cAMP pool. The logical next question is the cellular targets involved, especially during cell differentiation.

We recently showed [7] that AA inhibits the differentiation of adult preadipocytes into mature adipocytes. Recent papers [8-10] have shown that AA is able to reprogram adult cells and transform them into adult stem cells. This reprogramming is mediated by DNA demethylation [11], probably at specific loci and involving chromatin protein modifications.

However, there has been little investigation into AA and embryonic stem cells (ES cells). The most relevant paper, by Takahashi et al. [12], used high-throughput screening to demonstrate that AA is able to push ES cells to differentiate into cardiomyocytes.

Here we tested the hypothesis that AA is involved in the differentiation of mesoderm derivatives via a process that uses the p38MAPK/CREB pathway and probably involves chromatin remodelling. Here, using murine ES cells to allow differentiation with or without AA, we demonstrated that AA drives embryonic stem cells toward myogenic and osteogenic lineage differentiation and also inhibits adipogenesis. The mechanism of action involved in this differentiation process was also addressed. As aging is associated with a decrease in muscle and bone mass and an increase in fat mass that could result from modified mesenchymal cell differentiation during the cell renewal processes, we focus our discussion on the physiopathological implications of these findings.

\section{Material \& methods}

\subsection{Chemicals}

The study used p38 MAPK inhibitors (PD169316 and SB203580) from Merck Millipore, adenylate cyclase inhibitor (SQ 22536) from Tocris, primers (as listed in Table 1) from Eurogentec, and AA from Merck Millipore. AA was dissolved as needed in $1 \mathrm{X}$ PBS, then filtered and added at a final concentration of $50 \mathrm{mg} / \mathrm{mL}$ in neutral $\mathrm{pH}$ medium supplemented with $25 \mathrm{mM}$ HEPES buffer. Retinoic acid $\geq 98 \%$ was from Sigma-Aldrich. A $3 \mathrm{mg} / \mathrm{mL}$ solution was prepared in DMSO and stored in light-protected vials at $-20^{\circ} \mathrm{C}$ before dilution with tissue culture medium. All other reagents were from Sigma-Aldrich.

\subsection{ES cell culture}

CGR8 ES cells (kindly gifted by B. Binetruy) were cultured without feeder cells in RPMI 1640 (Roswell Park Memorial Institute) and in DMEM supplemented with pyruvate, non-essential amino acids, $\beta$-mercaptoethanol, $10 \%$ ES cellqualified fetal bovine serum, leukemia inhibitory factor (LIF), and $1 \%$ penicillin/streptomycin $(100 \mathrm{U} / \mathrm{mL}$ and $100 \mu \mathrm{g} / \mathrm{mL})$.
CGR8 cells were seeded at a density of $1 \times 10^{4}$ cells $/ \mathrm{cm}^{2}$ in $0.1 \%$ gelatin-coated plates with medium containing LIF. For proliferation tests, cells were seeded at a density of 1000 cells per plate. Cells were cultured for $24 \mathrm{~h}$ with the DMEM medium + LIF. Cells were induced to spontaneously differentiate by removing LIF and then cultured for 9 days with or without ascorbic acid. Cells were grown in an incubator held at $5 \%$ CO2. At day 9 of differentiation, adherent cells were enzymatically dissociated using $0.25 \%$ trypsin and $0.05 \%$ EDTA.

\subsection{Evaluation of muscular differentiation}

Differentiated ES cells treated or not with AA were washed and fixed at day 10 in 3\% paraformaldehyde for $15 \mathrm{~min}$ at room temperature (RT). Cell membranes were permeabilized in PBS-0.1\% Triton X-100 for $15 \mathrm{~min}$ at RT and incubated with an anti-sarcomeric MHC antibody (clone MF20, RD systems) or an anti-sarcomeric actinin antibody (EA-53, Abcam) in PBS-10\% fetal bovine serum for $1 \mathrm{~h}$. After three washes in PBS, cells were incubated with anti-mouse ALEXA488 or ALEXA546 (Invitrogen) for $1 \mathrm{~h}$ at RT then co-stained with DAPI (an example is presented in Supporting Information Fig. 1). A Zeiss fluorescence platform was used for cell imaging. We explored 10 areas, each encompassing about 100 cells, and assessed the percentage of muscular MHC-positive cells.

\subsection{Gene expression assays}

Total RNA was extracted from cells using TRIZOL reagent (Invitrogen $^{\mathrm{TM}}$ ) according to the manufacturer's protocol. To check RNA integrity prior to use, an Agilent 2100 Bioanalyzer was used to test the quality and concentration of each sample. Purified total RNA from differentiated cells was reverse-transcribed using SuperScript II reverse transcriptase (Invitrogen ${ }^{\mathrm{TM}}$ ) to produce cDNA. Quantitative real-time polymerase chain reaction (qRT-PCR) was then performed on a LightCycler 480 Real-Time PCR System (Roche) using UPL probes. Specific primers are described in Table 1. Expression levels of target genes were normalized using $\beta$-actin (ACTB) as internal standard. The results were processed using the comparative CT method where amount of the target, normalized to the endogenous reference and relative to a calibrator, is given by $2^{-\Delta \Delta \mathrm{CT}}$. Three independent reads were performed.

\subsection{Transfection by siRNA}

Transfection used two specific siRNA that were directed to SLC23A2 (encoding SVCT2) from Invitrogen ${ }^{\text {TM }}$ (HSS190749 and HSS190748) and the manufacturer-recommended negative control (Stealth RNAi $^{\mathrm{TM}}$ siRNA Negative Control 
Table 1. Specific primers used in qPCR experiments

\begin{tabular}{|c|c|c|}
\hline Gene name & Primer & Sequences $\left(5^{\prime} \rightarrow 3^{\prime}\right)$ \\
\hline \multirow[t]{2}{*}{$\alpha-\mathrm{MHC}$} & Forward & CGCATCAAGGAGCTCACC \\
\hline & Reverse & CCTGCAGCCGCATTAAGT \\
\hline \multirow[t]{2}{*}{$\beta-\mathrm{MHC}$} & Forward & GCCTCTGCGGACATTGATAG \\
\hline & Reverse & GGGCAGCTGGAAGATCACT \\
\hline \multirow[t]{2}{*}{ BMP-2 } & Forward & CGGACTGCGGTCTCCTAA \\
\hline & Reverse & GGGGAAGCAGCAACACTAGA \\
\hline \multirow[t]{2}{*}{ Runx2 } & Forward & GTGCCCAGGCGTATTTCA \\
\hline & Reverse & TGCCTGGCTCTTCTTACTGAG \\
\hline \multirow[t]{2}{*}{ CEBP $\alpha$} & Forward & AGCAACGAGTACCGGGTACG \\
\hline & Reverse & GTTTGGCTTTATCTCGGCTC \\
\hline \multirow[t]{2}{*}{ CEBP $\beta$} & Forward & AAGATGCGCAACCTGGAG \\
\hline & Reverse & CAGGGTGCTGAGCTCTCG \\
\hline \multirow[t]{2}{*}{ PPAR $\gamma$} & Forward & GAAAGACAACGGACAAATCACC \\
\hline & Reverse & GGGGGTGATATGTTTGAACTTG \\
\hline \multirow[t]{2}{*}{ Adiponectin } & Forward & TCCTGGAGAGAAGGGAGAGAAAG \\
\hline & Reverse & CAGCTCCTGTCATTCCAACAT \\
\hline \multirow[t]{2}{*}{ NF-L } & Forward & CCGAAGAGTGGTTCAAGAGC \\
\hline & Reverse & GTCCAAGGCCATCTTGACAT \\
\hline \multirow[t]{2}{*}{ NF-M } & Forward & GTGCGAGGCACTAAGGAGTC \\
\hline & Reverse & сССССТCTAGGAGTTTCСTG \\
\hline \multirow[t]{2}{*}{ GFAP } & Forward & CACGAACGAGTCCCTAGAGC \\
\hline & Reverse & GAATGGTGATGCGGTTTTCT \\
\hline \multirow[t]{2}{*}{ MBP } & Forward & ATCCAAGTACCTGGCCACAG \\
\hline & Reverse & TGTGTGAGTCCTTGCCAGAG \\
\hline \multirow[t]{2}{*}{ SVCT2 } & Forward & TGTGCCAGGCTCTCCTGT \\
\hline & Reverse & GACССTCCACGAAAATACCC \\
\hline \multirow[t]{2}{*}{ CREB } & Forward & ACATTAGCCCAGGTATCTATGCCAG \\
\hline & Reverse & ССTGAATGACTCCATGGACTTGAAC \\
\hline \multirow[t]{2}{*}{$\mathrm{p}$-CREB } & Forward & AGTTGGTCACGTAACTGGCTCA \\
\hline & Reverse & TGACAGCTCACGTCAAGGCAGC \\
\hline \multirow[t]{2}{*}{$\alpha-\mathrm{MHC}$ (ChIP-Seq) assay } & Forward & CCCACACAAGTCTCAGAGCA \\
\hline & Reverse & CATAGGGGACCGTAGCAAGA \\
\hline \multirow[t]{2}{*}{$\beta-\mathrm{MHC}$ (ChIP-Seq) assay } & Forward & CTGGCAGCTGTCTACTGAGT \\
\hline & Reverse & СCTCTTGACGTGTTTGTGGG \\
\hline \multirow[t]{2}{*}{ CEBP $\alpha$ (ChIP-Seq) assay } & Forward & CAGCAGACCTCCCTAACAGT \\
\hline & Reverse & CTCCATTTGTCCGTGTTCCG \\
\hline \multirow[t]{2}{*}{ PPAR $y$ (ChIP-Seq) assay } & Forward & TTGTGGGGTCTGGATCTGAC \\
\hline & Reverse & TCACTTGGTCACTCTCCGTC \\
\hline \multirow[t]{2}{*}{$\beta$-actin } & Forward & CTAAGGCCAACCGTGAAAAG \\
\hline & Reverse & ACCAGAGGCATACAGGGACA \\
\hline
\end{tabular}

Kit). One day before transfection, cells were plated in 6-well microplates at a density of $5 \times 10^{5}$ cells/well in DMEM with $10 \%$ fetal calf serum, then incubated at $37^{\circ} \mathrm{C}$ in a humid $5 \% \mathrm{CO} 2$ atmosphere. Following the manufacturer's (Invitrogen) protocol, the siRNA Lipofectamine ${ }^{\mathrm{TM}}$-plus-cell complex was first rinsed with $1 \mathrm{X}$ PBS before transfection in order to remove residual serum present in the initial culture medium. For each transfection, 100 pmoles of siRNA (20 $\mu \mathrm{M}$ stock) and $5 \mathrm{~mL}$ of Lipofectamine ${ }^{\mathrm{TM}} 2000$ were mixed in $250 \mu \mathrm{L}$ of Opti-MEM ${ }^{\circledR}$ I reduced serum medium. This transfection complex was added to each well containing $1.75 \mathrm{~mL}$ of Opti-MEM ${ }^{\circledR}$ I reduced serum medium. The plates were then incubated at $37^{\circ} \mathrm{C}$ in a humid $5 \% \mathrm{CO} 2$ atmosphere for $24 \mathrm{~h}$. After incubation, transfection reactions were replaced by $2 \mathrm{~mL}$ of AA solutions without serum. The medium was then removed and replaced by the same medium with serum. At
9 days after transfection, cells were harvested for qRT-PCR analysis. No nonspecific cell death due to possible toxic effects of transfection was detected.

\subsection{Chromatin immunoprecipitation and genomic qPCR}

ES cells were allowed to differentiate, with or without AA, for 10 days. Cells were then collected and chromatin immunoprecipitation (ChIP) was performed at a crosslinking time of 10 min using an anti-H3K27me3 antibody (Diagnode, C15410195). Antibodies were thus coupled to a Millipore Magna ChIP ${ }^{\mathrm{TM}}$ kit (Millipore) by overnight incubation at $4^{\circ} \mathrm{C}$. The following day, chromatin was added to the antibody-bead complexes and incubated overnight at $4^{\circ} \mathrm{C}$. The 
Table 2. Number of beating plaques in CGR8 cells cultures with $0.1 \mathrm{mM}$ of $A A$ and different inhibitors in a surface of $1600 \mu^{2}$

\begin{tabular}{lll}
\hline & + AA - inhibitor & + AA + inhibitor \\
\hline SO & 11 & 2 \\
siRNA versus SVCT2 & 8 & 2 \\
SB & 8 & 1 \\
\hline
\end{tabular}

bound complexes were washed three times in low-salt solution, twice in high-salt solution, once in $\mathrm{LiCl}$ and twice in Tris/EDTA (TE) buffer. DNA was extracted from beads by standard phenol/chloroform extraction, then precipitated and resuspended in $30 \mu \mathrm{L} \mathrm{H}_{2} \mathrm{O}$. To quantify the results, qPCR reactions were performed in triplicate (precipitated DNA samples as well as serially-diluted input DNA) using a Roche LightCycler 480 qPCR machine. The input DNA was diluted 10 times before $q P C R$. Specific primers were designed for $\alpha$-MHC, $\beta$-MHC, PPAR- $\gamma$, CEBP $\alpha$ and $\beta$-actin genes (Table 2). The PCR program was $7 \mathrm{~min}$ at $95^{\circ} \mathrm{C}, 95^{\circ} \mathrm{C}$ for $15 \mathrm{~s}$, and $60^{\circ} \mathrm{C}$ for $60 \mathrm{~s}$ for 45 cycles. The data were analyzed and $\mathrm{Ct}$ values were recorded to evaluate the fold difference between experimental samples and normalized input.

$\Delta \mathrm{Ct}$ (normalized ChIP) $=\mathrm{Ct}$ ChIP - Ct Input - log2 (input dilution factor). "\% of Input" (a value that represents the enrichment of certain histone modifications on a specific region) was calculated for each sample, as follows: \% of Input $=100 / 2^{\Delta \mathrm{Ct}[\text { normalized ChIP] }}$.

As a control, we evaluated the amount of promoter of a houskeeping gene ( $\beta$-actin) present in H3K27me3 immunoprecipitated chromatin.

\subsection{Statistical analysis}

Statistical analysis was performed using Prism v5 software (Graphpad). Results were analyzed for all biological replicates, with three reads for four independent analyses, using the Mann-Whitney two-tailed statistical significance test with a confidence interval of $95 \%$. A $p$ value lower than 0.05 was considered significant.

\section{Results}

\subsection{AA and ES cell differentiation}

Proliferation of murine ES cells (CGR8) was tested with or without AA. As shown in Fig. 1, proliferation was reduced when LIF was removed from the culture medium. When $0.1 \mathrm{mM}$ of AA was added, proliferation was not impaired, but when $0.5 \mathrm{mM}$ of AA was added, proliferation stopped. Therefore, for further experiments, AA was mainly used at a concentration of $0.1 \mathrm{mM}$ to not disrupt proliferation. Note that this concentration is in the physiological range of concentrations observed in different tissues.

Cells were simply allowed to spontaneously differentiate by removing LIF from the medium to stop proliferation, without adding any additional molecules other than AA. Fate of ES cells incubated with AA was evaluated by adding AA to ES cell cultures for 9 days. Results showed that without AA, 40\% of cells differentiated into muscle cells, cells were labeled using an antibody labelling muscle cells (sarcomeric $\mathrm{MyH}$ or actinin), and that $75 \%$ of cells differentiated into muscle cells when AA was added to the ES cell culture whereas less than $1 \%$ differentiated when retinoic acid (RA) was added (Fig. 2A and Supporting Information Fig. 1). qPCR was used to evaluate the expression of a cardiac marker (cardiac $\alpha$-Myosin Heavy Chain) with or without treatment of ES cells with AA. Results showed that AA stimulated cardiac marker expression (Fig. 2B). Finally, treatment with AA led to the formation of plaques of beating cells (Fig. 2C and videos), suggesting that AA drove mesenchymal cells toward muscle differentiation. In parallel, we tested the expression of markers involved in myogenesis (cardiac MHC $\alpha$ and $\beta$ ), osteogenesis (BMP2, Runx2), neurogenesis (NF-L, -M), glial cell differentiation (GFAP and MBP), and adipogenesis (CEBP $\alpha$ and $\beta$, PPAR $\gamma$ and adiponectin). Results showed that AA stimulated the expression of markers involved in myogenesis and osteogenesis

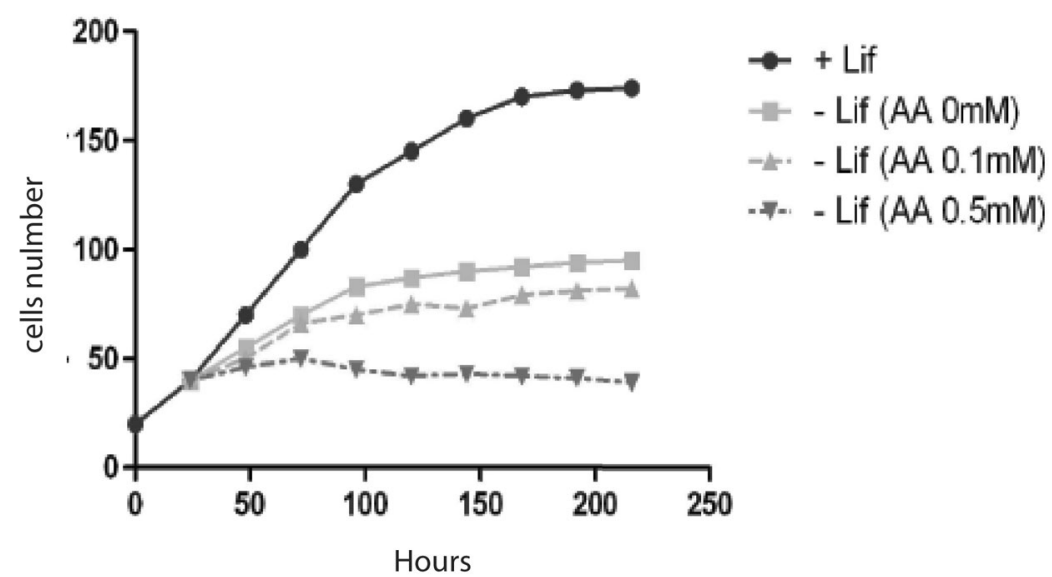

Figure 1. ES cells (CGR8) were seeded at a density of $1000 \mathrm{cells} / \mathrm{cm}^{2}$ in 6 -well microplates and incubated in presence or absence of AA and with or without LIF. Number of cells was evaluated from to to $220 \mathrm{~h}$. $\mathrm{Y}$-axis plots cell number $\times 10^{-2}$. 


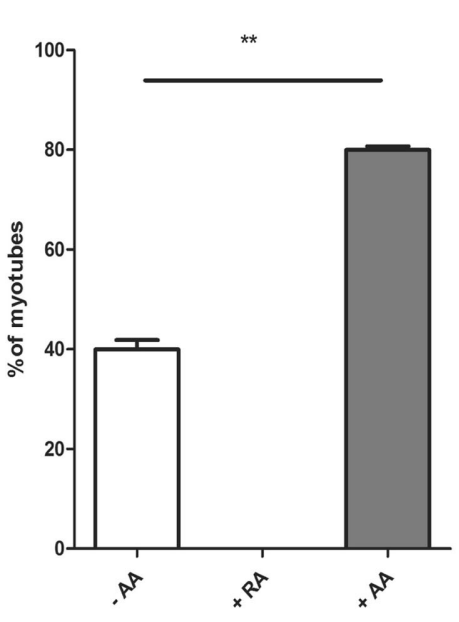

A

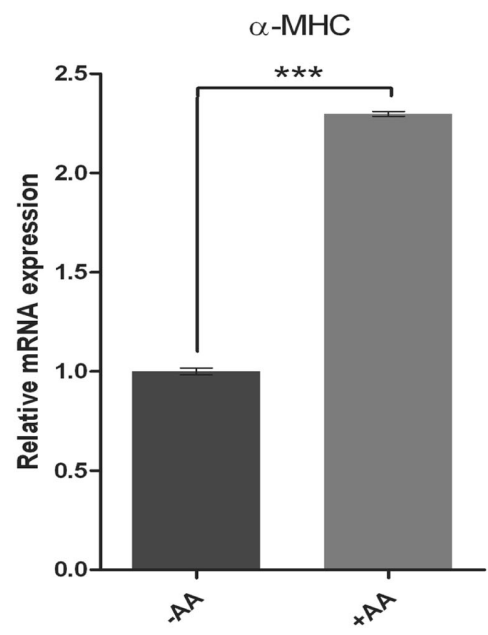

B

Figure 2. ES cells (CGR8) were incubated with either retinoic acid (RA) or ascorbic acid (AA) at D0 and for 10 days. A. Cells were stained with an anti-MHC antibody (see Methods) and percentage of positive cells was evaluated. B. Expression of cardiac $\alpha-\mathrm{MHC}$ in ES cells treated or not with AA $(0.1 \mathrm{mM})$ was evaluated using qPCR. C. Evaluation of areas presenting beating cells (10 000 plated cells).

and inhibited the expression of markers involved in neurogenesis and adipogenesis (Fig. 3).

\subsection{The p38 MAPK/CREB pathway drives muscle differentiation}

A study on Xenopus development showed that mesoderm differentiation is under the control of the p38 MAPK/CREB pathway [13]. We thus tested whether the AA-driven differentiation of mammalian ES cells into muscle is also under the control of p38 MAPK. A chemical inhibitor of p38 MAPK activity (SB203580) was added to ES cell cultures incubated with AA, and we then probed the expression of cardiac markers. As shown in Fig. 4A, inhibition of p38 activity inhibited the expression of cardiac markers. To confirm these data, we treated cells with another inhibitor (PD169316) and observed the same results (data not shown). In addition, the number of beating areas in the ES culture was reduced by treatment with SB203580 (Table 2).

In order to dig deeper into the mechanism, extracts of ES cells, incubated or not with AA, were probed with an antibody raised against phosphorylated CREB. As shown in Fig. 4B, AA inhibited CREB phosphorylation, although this mechanism did not appear to involve changes in CREB levels, which remained constant (Supporting Information Fig. 2).

\subsection{Transporter SVCT2 is involved in ES cell differentiation}

No classical receptor of AA has been described so far. However, SVCT2, a membrane protein, binds AA with a high affinity and transports AA into cells. Note that this transport is very AA-specific $[14,15]$. SVCT2 protein could thus act in signaling pathways involved in the differentiation of ES cells by transduction of AA signaling. As the transporter activity of SVCT2 is dependent on $\mathrm{Na}^{+} / \mathrm{K}^{+}$pump activity, we disrupted the $\mathrm{Na}^{+} / \mathrm{K}^{+}$pump using ouabain and probed the expression of cardiac markers (cardiac $\alpha$ and $\beta$-MHC). As shown in Fig. $4 \mathrm{C}$, ouabain inhibited the expression of these cardiac markers in AA-treated ES cells. Moreover, siRNA directed to SVCT2 gene expression transfected into ES cells inhibited 75\% of SVCT2 expression (data not shown). As shown in Fig. 4D, inhibition of SVCT2 expression inhibited the expression of cardiac muscle markers of ES cells treated with AA. Moreover, treatment of ES cells with anti-SVCT2 siRNA reduced the density of beating areas in the cultures (Table 2).

To investigate the involvement of adenylate cyclase (ADC) as a putative intermediate between SVCT2 and p38/CREB, based on the action of AA on adenylate cyclase activity [5], cells were incubated with an ADC inhibitor (SQ 22536) and the expression of cardiac MHC markers was quantified. As shown in Fig. 4E, SQ 22536 treatment repressed the expression of muscle-specific markers and reduced the number of beating areas in cultures (Table 2), suggesting that ADCs were involved in the process.

\subsection{Windows of ES cell sensitivity to AA}

To investigate the windows of effect of AA on ES cells, CGR8 cells were treated with AA for different time-periods (from 0 to 10 days, from 0 to 3 days, or from 3 to 10 days), and the expression of cardiac muscle cell markers ( $\alpha$ and $\beta$-MHC) 


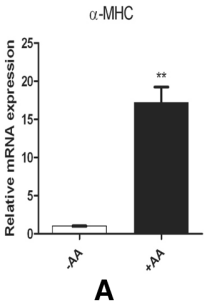

CEBP $\alpha$

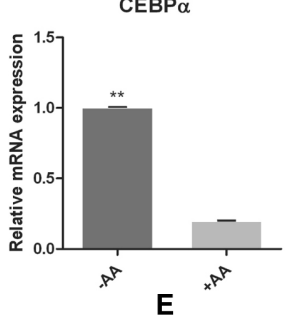

NF-L

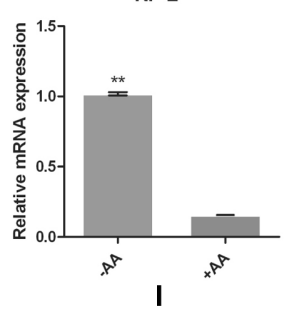

Myogenic and osteogenic markers
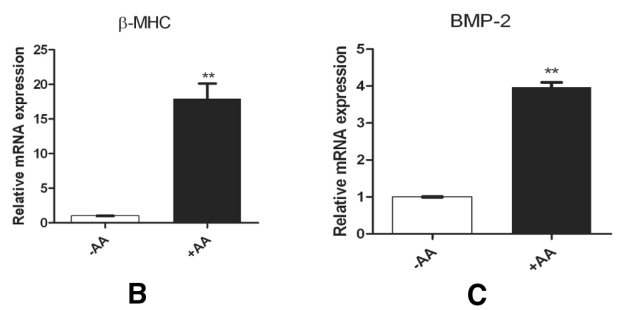

Adipogenic markers
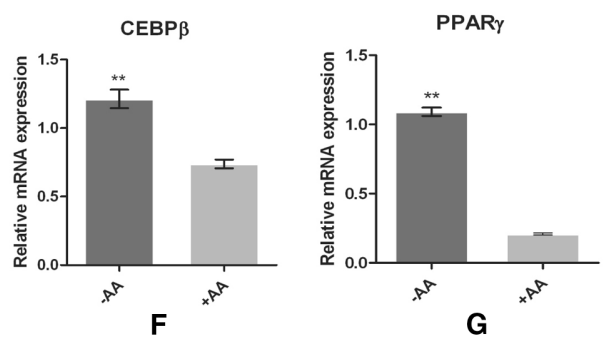

Neurogenic markers
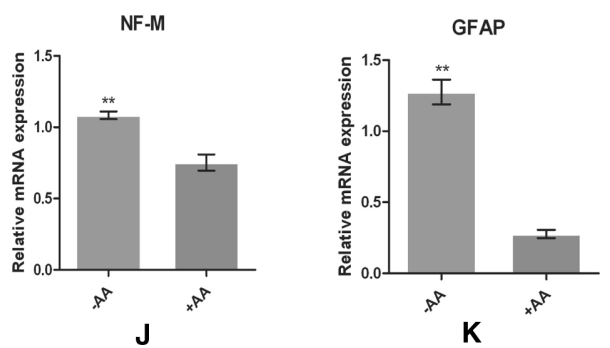
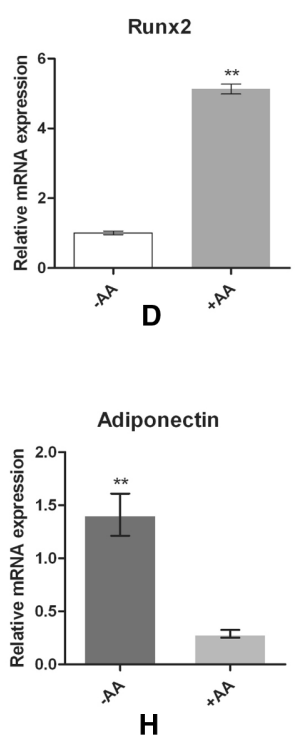

MBP

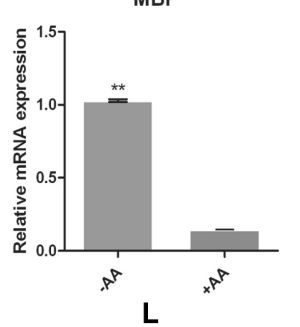

Figure 3. ES cells (CGR8) were incubated with or without ascorbic acid (AA) for 10 days, without LIF. After extraction of RNAs, we evaluated relative expression of specific markers: muscle $\mathrm{MHC}$ ( $\mathbf{A}$ and $\mathbf{B})$ as markers of myogenesis, BMP and Runx2 (C and $\mathbf{D})$ as markers of osteogenesis, CBBP $\alpha$ and $\beta(\mathbf{E}, \mathbf{F})$, PPAR- $\gamma$ (G) and adiponectin (H) as markers of adipogenesis, NF-L and M $(\mathbf{I}, \mathbf{J})$ as neuronal markers, GFAP (K) and MBP (L) as glial markers. was evaluated (Fig. 5). Results showed that ES cells were only sensitive to AA stimulation at early stages of the culture (from 0 to 3 or 10 days). Treating cells with AA after 3 days of culture had very little impact on differentiation.

\subsection{AA and RA act in competition}

To explore the effect of competition between AA and RA, two sets of experiments were performed. In the first set, ES cells were treated with a constant RA concentration $(0.01 \mathrm{mM})$ and increasing AA concentrations (from 0.01 to $0.25 \mathrm{mM}$ ), and gene expression of neuronal markers (NF-L and NF-M; Fig. 6A and B), glial markers (GFAP and MBP; Fig. 6C and D) and muscle markers ( $\alpha$ and $\beta$ MHC; Fig. 6E and F) was quantified. The data confirmed that AA inhibited RA-mediated neuronal and glial differentiation and upregulated the expression of muscle cell markers.

In the second set, ES cells were treated at constant AA concentration $(0.01 \mathrm{mM})$ and increasing RA concentrations, and we quantified gene expression of neuronal markers (Fig. 7A and B), glial markers; Fig. 7C and D) and muscle markers (Fig. E and F) was quantified. Increasing RA concentration drove ES cell differentiation from muscle cells toward neuronal differentiation, suggesting that RA inhibited muscle differentiation.

\subsection{AA and chromatin remodeling}

Finally, we evaluated whether the action of AA on the transcription of tissue-specific genes could involve changes in histone modifications. It has recently been shown that AA is able to modulate chromatin structure in adult cells, and thus to reprogram it (see introduction). We thus performed ChIP using an antibody raised against modified histones associated with repressed genes (H3K27me3) on the DNA of cells incubated or not with AA. Genomic qPCR was used to evaluate $\mathrm{H} 3 \mathrm{~K} 27 \mathrm{me} 3$ enrichment at the promoters of genes involved in myogenesis and adipogenesis. As shown in Fig. 8 (A and $\mathrm{B}$ ), treatment with AA resulted in decreased $\mathrm{H} 3 \mathrm{~K} 27 \mathrm{me} 3$ levels at the promoters of $\alpha$ and $\beta$ cardiac MHC genes but increased H3K27me3 levels at adipogenic genes (PPAR $\gamma$ and CEBP $\alpha$; Fig. $8 \mathrm{C}$ and D). Note that H3K27me3 levels were low at the promoter of the highly expressed gene $\beta$-actin and with no difference between AA-treated and non-AA-treated samples, demonstrating the specificity of the ChIP results (Fig. 8E). Overall, these results suggest a plausible role of AA-mediated signaling as a driver of chromatin remodeling. 


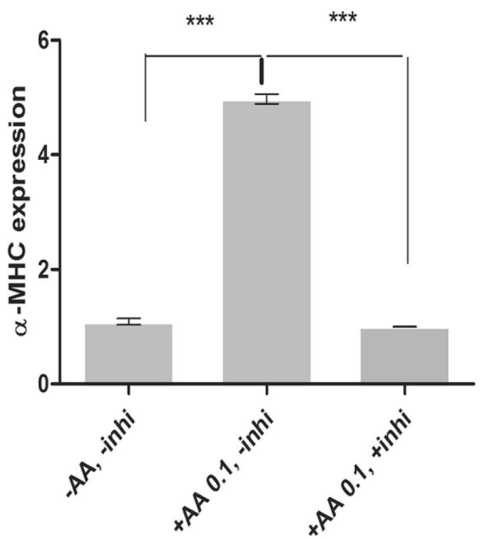

A

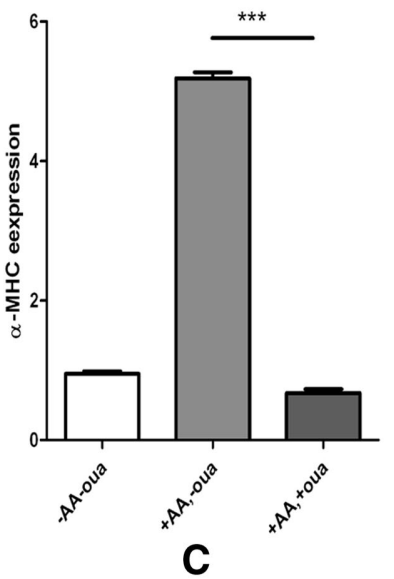

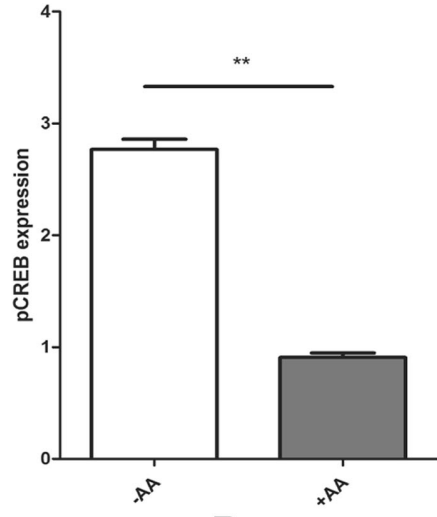

B
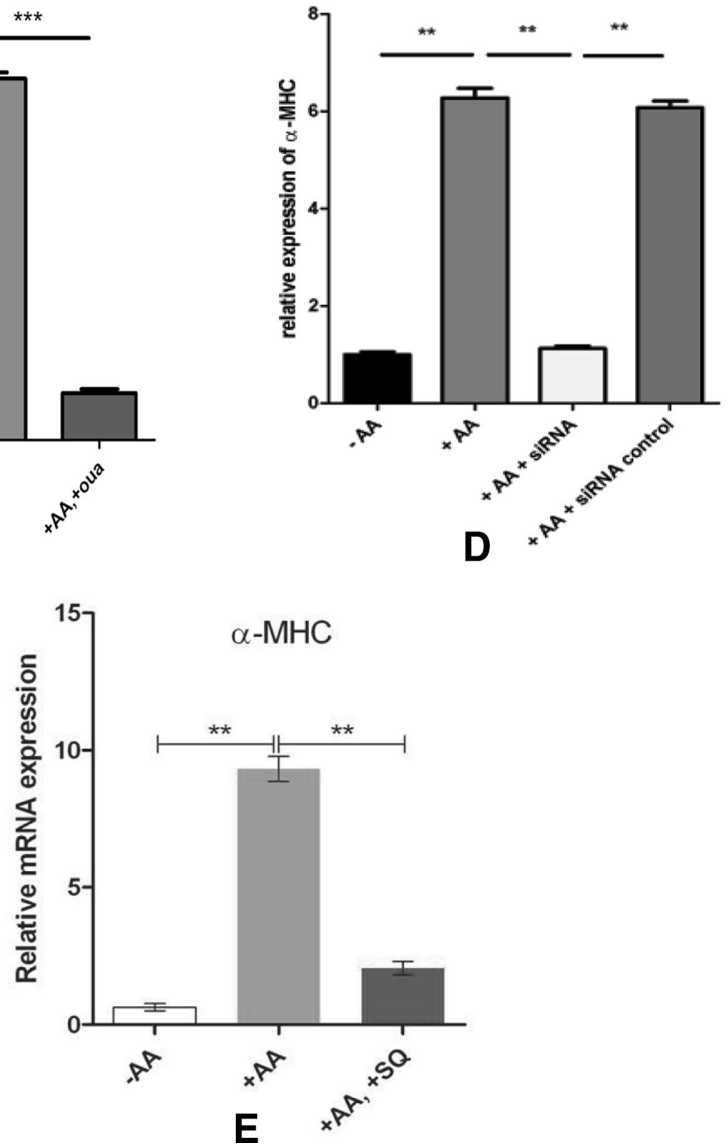

Figure 4. A. ES cells incubated or not with $A A$ were treated with or without a p38 MAP kinase inhibitor (SB 203380) for 10 days. Cells were lysed and RNAs were extracted. Expression of cardiac $\alpha-\mathrm{MHC}$ was evaluated using qPCR. B. In an independent experiment, ES cells were lysed at the end of the protocol before Western blotting. Phosphorylated CREB expression was analyzed using an antibody recognizing the phosphorylated form of this protein. Western blots were scanned and band intensity was evaluated using imageJ. C. ES cells incubated with or without AA were treated with ouabain. Cardiac $\alpha$ MHC expression was evaluated using qPCR. D. ES cells were transfected or not with a SVCT2specific siRNA or with a negative control siRNA (see Methods). Expression of cardiac $\alpha-\mathrm{MHC}$ was evaluated using qPCR. E. ES cells cultured with or without $A A$ were treated with an adenylate cyclase inhibitor (SQ22536). Expression of $\alpha-\mathrm{MHC}$ was evaluated using qPCR.

\section{Discussion}

Several micronutrients are known to play a role in embryonic processes. Retinoic acid (RA, the active substance of vitamin A) is the best example. During gastrulation, the formation of the three primary germ layers involves the expres- sion of Wnt/B-catenin as well as FGF signaling pathways [16]. The expression of these genes is controlled by the gradient of RA. Thus, our hypothesis was that ascorbic acid (AA) could also play a role in embryogenesis in much the same way as RA. However, there are only a few indications of action of AA on primary germ layer formation or on the 

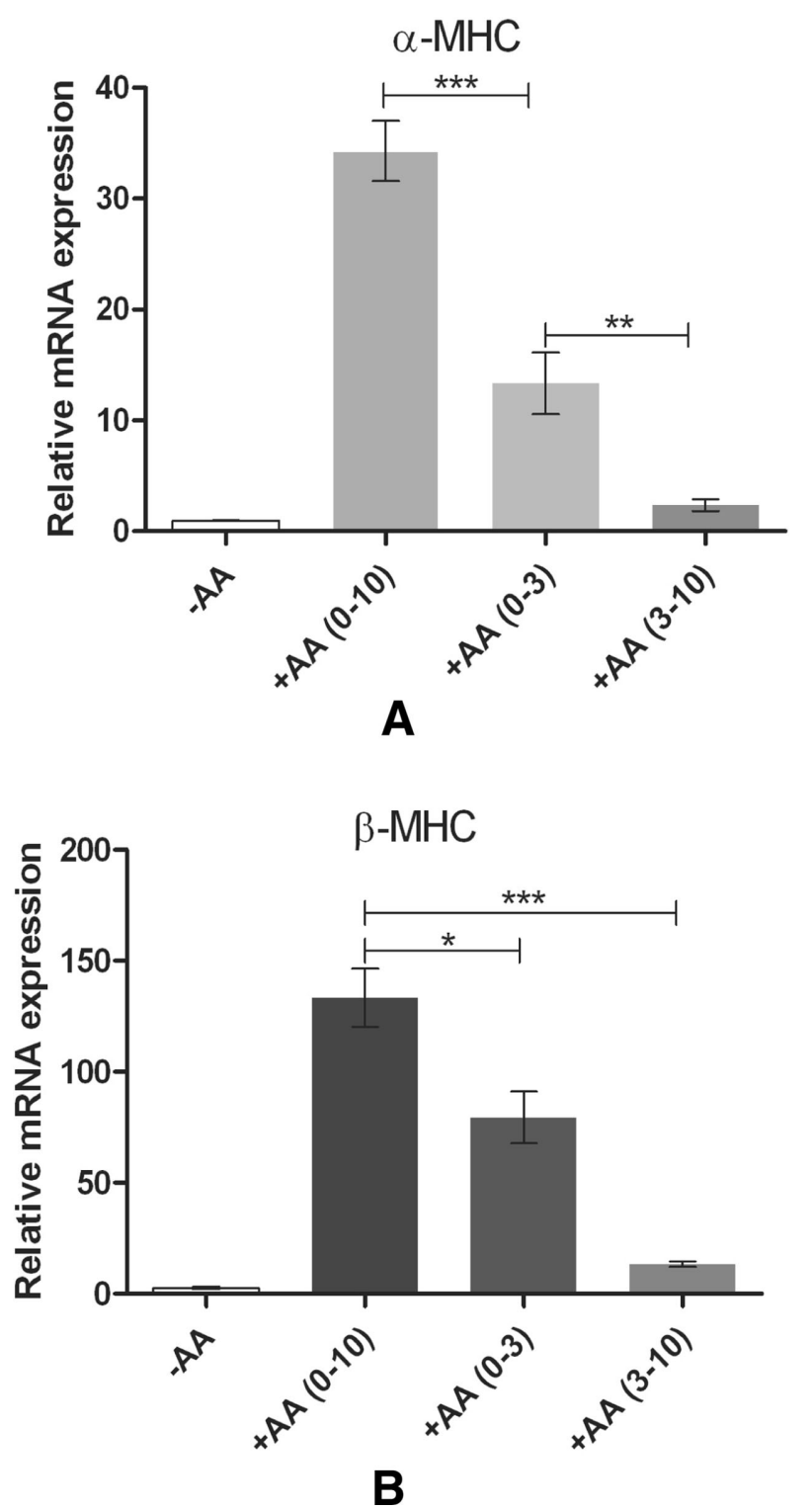

Figure 5. ES cells were treated with AA from day 0 to day 10 , from day 0 to day 3 or from day 3 to day 10. RNAs was extracted. $\alpha$ and $\beta$-cardiac MHC was evaluated using qPCR.

differentiation of cell types derived from one of these three layers. We therefore set up experiments to evaluate the potential impact of AA on embryonic stem cell differentiation as a model of embryonic differentiation. For this purpose, we used totipotent cells (ES cells) derived from murine embryonic stages (CGR8 line). These cells are able to differentiate into all cell types and thus make a good tool for investigating the potential impact of AA in cell differentiation processes. The main finding of this study is that AA promotes mesodermic cell differentiation toward myogenesis and osteogenesis and inhibits adipogenesis. The following discussion focuses on different mechanisms potentially involved in these processes and tested here.

\subsection{AA and ES cell differentiation}

Totipotent CGR8 murine ES cells were used to explore the potential involvement of AA in embryonic differentiation. The differentiation of ES cells, incubated or not with AA, was evaluated using (i) cell morphology and specific function (such as spontaneously beating cells for cardiac myocyte differentiation) and (ii) expression of markers specifically expressed in specific cell lineages, including skeletal muscle, bone, adipose tissue, and neuron/glial cells. The data reported here demonstrate that AA drives ES cell differentiation toward myogenesis and osteogenesis and inhibits adipogenesis. We observed that AA is required at concentrations in the physiological range observed in human tissue (100 $\mu \mathrm{M}$, see below). Takahashi et al [12] had already suggested that AA is involved in cardiomyogenesis based on a study using high-throughput screening in the same ES cell strain as here. Crescini et al. [17] reported that cardiomyocyte development was rescued in FGFR1-knockdown mice using AA. Analysis of the expression of different genes prompted the authors to conclude that AA acts downstream of the FGFR pathway.

Our results and the scant literature converge to suggest that AA probably acts on mesoderm differentiation.

Other studies report contradictory results [18-23] suggesting that AA pushed cells to differentiate into adipogenesis or neurogenesis. However, either cell status and/or the protocols used to promote cell differentiation were different to those used here. Other studies used already-committed cells, VM embryonic cells [18], cells from PCOS patients [21], embryonic carcinoma P19 cells [23] or different ES R1 lines [19], and added different molecules in the culture media, from $\beta F G F$ [18] or complex cocktail [20] to activinA+BMP4 [22]. As ES cell differentiation appears dependent on context, level of commitment, added molecules, differentiation protocol, and other factors, we opted to use totipotent cells here in a protocol allowing spontaneous cell differentiation without added molecules in culture media.

\subsection{Mechanisms involved in AA-mediated ES cell differentiation}

Keren et al. [13] showed that the p38 MAPK/CREB pathway is involved in mesoderm patterning and that differential p38 MAPK/CREB pathway activity (p38 phosphorylation, activating CREB probably by CREB phosphorylation) likely regulates dorso-ventral patterning in Xenopus embryo. Their data suggest that this pathway is downstream of the maternal Wnt pathway as well as expression of the organizer genes siamois and goosecoid. Here, and consistently with Keren et al [13], we confirm that ES cell differentiation into myoblast or osteoblast progenitors involves the p38MAPK/CREB pathway, and we further suggest that ADCs activities are involved upstream in this process. These data raise the question of the upstream (receptor) or downstream actors in this process. 
NF-L

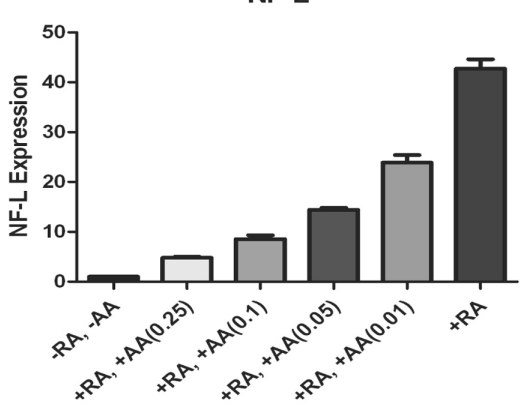

A
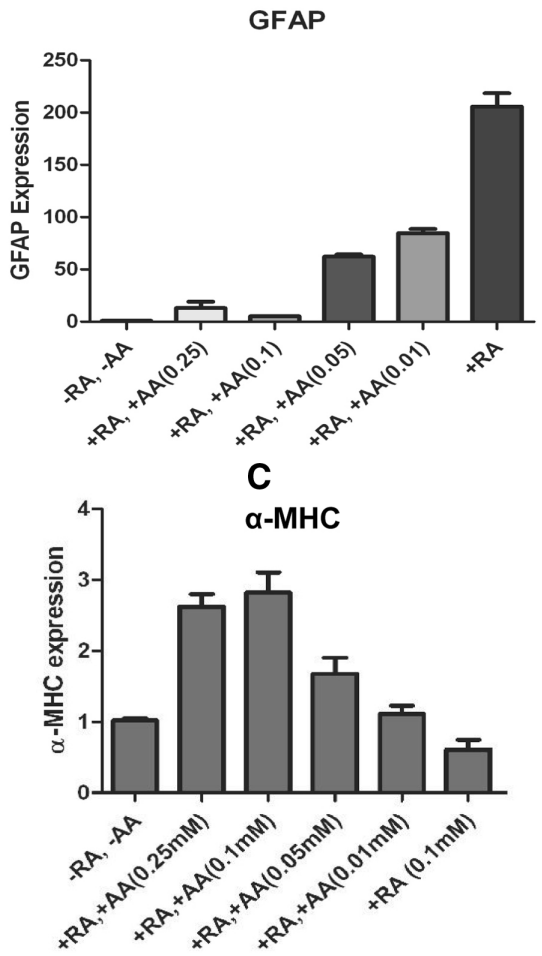

$E$

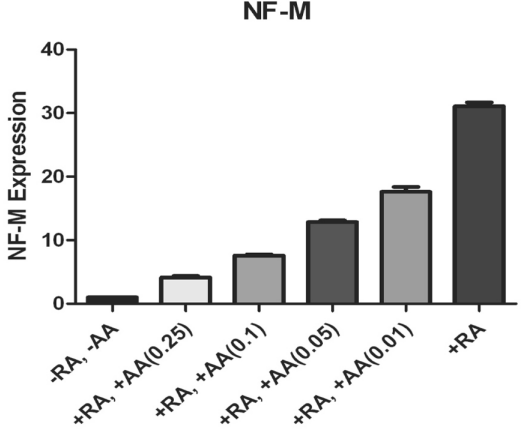

B
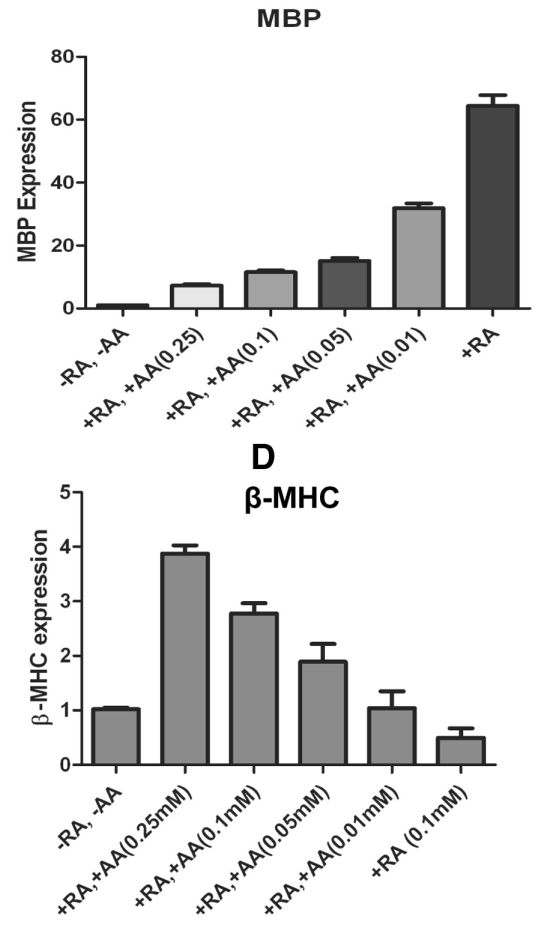

$\mathbf{F}$
Figure 6. ES cells were incubated with RA $(10 \mu \mathrm{M})$ and with increasing doses of $A A$. Expression of neuronal (NF-L and $M, A, B$ ), glial (GFAP, MBP, C, D) and cardiac muscle markers ( $\alpha$ and $\beta$ MHC, E, F) was evaluated using $\mathrm{qPCR}$.

\subsection{Reception and transduction of AA signaling}

We know that SVCT2 is a protein necessary for AA entry into cells through a $\mathrm{Na}+/ \mathrm{K}+$ pump. SVCT2 protein is highly conserved (70\% identity between human and drosophila), and only AA is efficiently transported. In addition, the SVCT2 knockdown model presents anomalous differentiation of various tissues, including peripheral nerves $[24,25]$. While receptors have been described for RA and vitamin D, no true receptor for AA has been isolated so far. A recent article [26] describes the role of SVCT2 in the differentiation of embryonic cells, and Meredith et al. [27] using mice invalidated/truncated for SVCT2 found an impact of AA level on embryonic neurotransmitter expression, mediated through the presence of SVCT2. These different reports argue for a role of SVCT2 in AA reception and transduction. Meredith et al. also reported that SVCT2 is poorly expressed in the embryonic brain when neuroblasts are highly proliferating, yet highly expressed in neonatal and adult brain when neuronal cells stop dividing and differentiate. This demonstrates that SVCT2 is differentially expressed during embryogenesis.

\subsection{AA and RA act in competition}

We demonstrated that AA is involved in the differentiation of mesodermal cells in different types of cells, but does AA play a role in other primary germ layers? It is well known that $\mathrm{RA}$ is involved in neuronal differentiation of neuroectoderm. The morphology and expression of specific markers indicated that RA pushes ES cells forward to differentiate into neurons and glial cells. However, experiments incubating RA with 


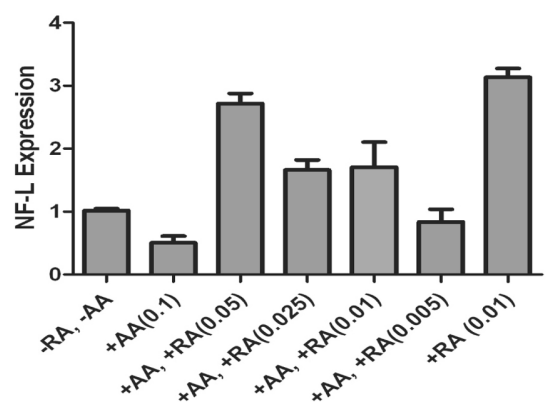

A
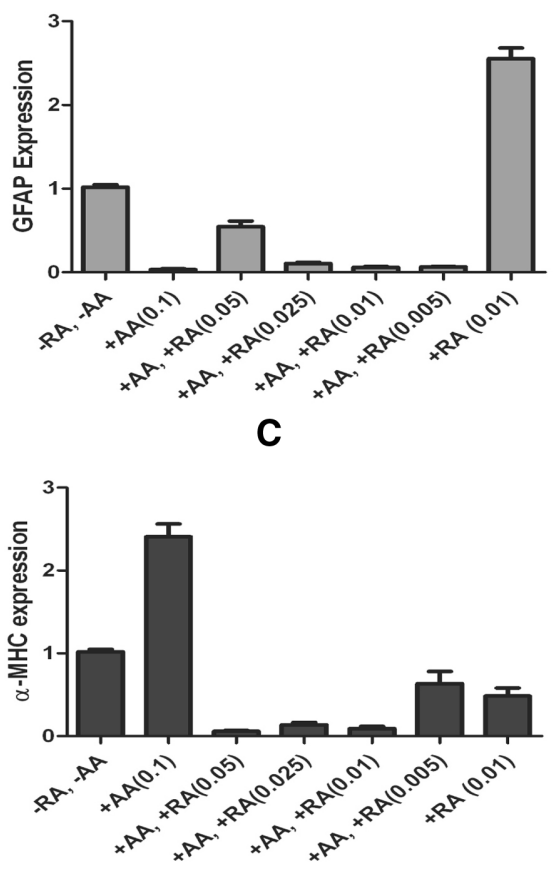

$E$

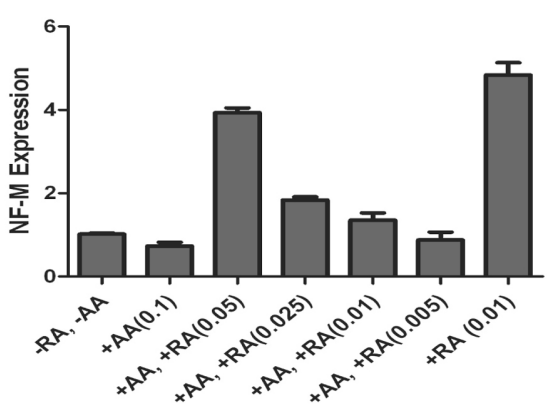

B
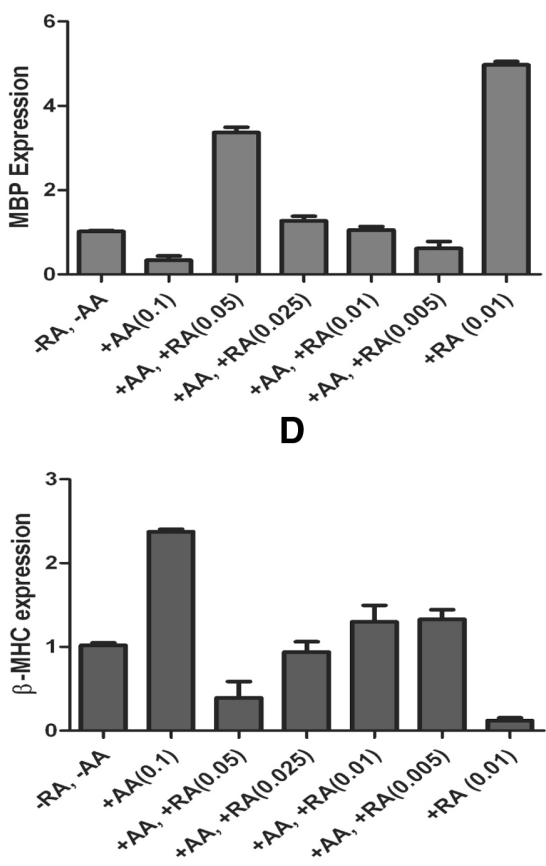

$\mathbf{F}$

Figure 7. ES cells were incubated with $\mathrm{AA}(0.1 \mathrm{mM})$ and with increasing doses of RA. Expression of neuronal (NF-L and $\mathrm{M}, \mathrm{A}, \mathrm{B})$, glial (GFAP, MBP, C, D), and cardiac muscle markers $(\alpha$ and $\beta$ MHC, E, F) was evaluated using qPCR.

increasing doses of AA demonstrated that increasing the AA doses inhibits RA-promoted neurogenic differentiation. Moreover, the reverse was observed for myogenesis: increasing the RA doses inhibited AA-promoted myogenesis. This suggests that high levels of RA and low levels of AA push mesodermal cells to differentiate into neuronal lineages. Low concentrations of RA and high concentrations of AA push cells to differentiate toward muscle (and probably bone). These data suggest that these two molecules operate competitively.

\subsection{AA as epigenetic regulator?}

It has been demonstrated that in adult cells AA act in cellular reprogramming and generation of iePSC cells through chromatin remodeling [8-11] in a process mediated by action on methylase/demethylase systems. Indeed, recent studies on AA-mediated cell reprogramming in adults cells $[10,11]$ demonstrated that AA acts through modulation of demethylase activity and modification of histone code. Here we suggest that AA acts on ES cell differentiation by opening or closing chromatin domain-overlapping promoters of specific genes. This mechanism results in expression of specific markers and drives the differentiation of mesodermal derivatives in different tissues while inhibiting the differentiation of others. The next step will be to understand the mechanism involved in epigenetic chromatin remodeling involving AA. A recent paper [28] demonstrated that proteins in the polycomb group are involved in this process during myoblast differentiation. More precisely, a PRC2-Ezh2 complex is removed from promoters of genes involved in myogenesis during myoblast differentiation, allowing the expression of key genes (e.g. MyoG, MHC). The mechanism implicated in this chromatin remodeling process is not fully understood but almost certainly involves enzymes modifying proteins from chromatin (i.e. kinases, demethylases, deacetylases). 


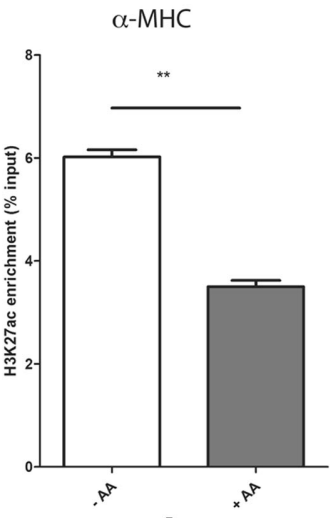

A

CEBP- $\alpha$

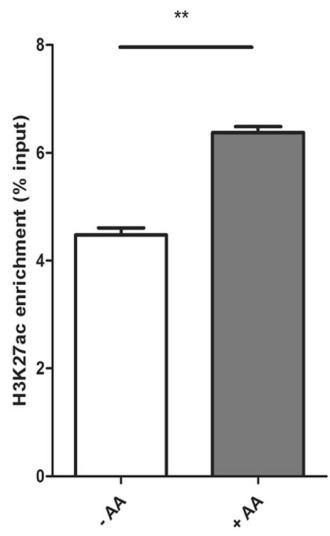

D

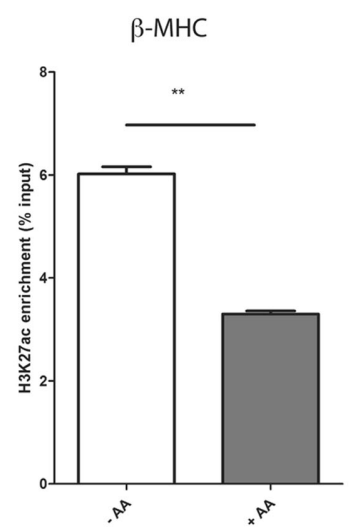

B

$\beta$-Actin

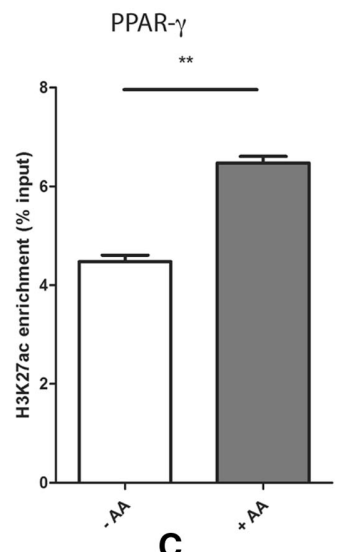

C
Figure 8. A. ES cells were incubated for 9 days with or without $A A(0.1 \mathrm{mM})$. Chromatin was extracted (see Methods) and immunoprecipitated using an antibody raised against $\mathrm{H} 3 \mathrm{~K} 27 \mathrm{ac}$ (see Methods). DNA was extracted and presence of the promotor of selected genes in the immunoprecipitated fraction was evaluated using genomic qPCR. Four genes were selected: $\alpha \mathrm{MHC}(\mathbf{A}), \beta \mathrm{MHC}(\mathrm{B}), \mathrm{PPAR} \gamma$ (C), CEBP $\alpha$ (D). Promotor of cytoplasmic actin was also evaluated as a control (E). Results are expressed as $\%$ of input' in the ChIP fraction.

$\mu \mathrm{M})$ is only achievable by oral intake. We previously reported that patients treated with $3 \mathrm{~g} /$ day of AA had an average plasma AA concentration of $106 \mu \mathrm{M}$ (up to $160 \mu \mathrm{M}$ in some patients) and that this dose is safe for human [35].

This manuscript was edited by Technical and Scientific Translation Company (ATT, Clermont-Ferrand, France). Experiments run by the laboratory received funding under a recurrent budget (Aix-Marseille University and INSERM). The authors thank $B$. Binetruy for providing the CGR8 cells and for further assistance on cell culturing and differentiation monitoring.

F.R. and B.B. performed the experiments. J.F.L. and M.F. designed and coordinated the experiments. R.C., M.D., and S.S. designed and participated in the chromatin immunoprecipitation experiments. F.P. contributed to the cell culture and Western Blots experiments.

\section{References}

[1] Padayatty, S. J., Sun, H., Wang, Y., Riordan, H. D. et al., Vitamin C pharmacokinetics: implications for oral and intravenous use. Int. Med. 2004, 140, 533-537. 
[2] Ha, M. N., Graham, F. L., D'Souza, C. K., Muller, W. J. et al., Functional rescue of vitamin $\mathrm{C}$ synthesis deficiency in human cells using adenoviral-based expression of murine Igulono-gamma-lactone oxidase. Genomics 2014, 83, 482492.

[3] Passage, E., Norreel, J. C., Noack-Fraissignes, P., Sanguedolce, V. et al., Ascorbic acid treatment corrects the phenotype of a mouse model of Charcot-Marie-Tooth disease. Nat. Med. 2004, 10, 396-401.

[4] Kaya, S., Belin, S., Bourgeois, P., Micaleff, J. et al., Ascorbic acid inhibits PMP22 expression by reducing cAMP levels. Neuromuscul. Disord. 2007, 17, 248-253.

[5] Kaya, F., Belin, S., Diamantidis, G., Fontes, M., Ascorbic acid is a regulator of the intracellular cAMP concentration: Old molecule, new functions? FEBS Lett. 2008, 582, 3614-3618.

[6] Belin, S., Kaya, F., Duisit, G., Giacometti, S. et al., Antiproliferative effect of ascorbic acid is associated with the inhibition of genes necessary to cell cycle progression. PLoS One 2009, 4, e4409.

[7] Rahman, F., Al Frouh, F., Bordignon, B., Fraterno, M. et al., Ascorbic acid is a dose-dependent inhibitor of adipocyte differentiation, probably by reducing cAMP pool. Front Cell Dev. Biol. 2014, 2, 29.

[8] Esteban, M. A., Wang, T., Qin, B., Yang, J., Qin, D. et al., Vitamin $C$ enhances the generation of mouse and human induced pluripotent stem cells. Cell Stem Cell 2010, 6, 7179.

[9] Stadtfeld, M., Apostolou, E., Ferrari, F., Choi, J., Walsh, R. M. et al., Ascorbic acid prevents loss of Dlk1-Dio3 imprinting and facilitates generation of all-iPS cell mice from terminally differentiated B cells. Nat. Genet. 2012, 44, 398-405.

[10] Wang, T., Chen, K., Zeng, X., Yang, J., Wu, Y. et al., The Histone demethylases $\mathrm{Jhdm} 1 \mathrm{a} / 1 \mathrm{~b}$ enhance somatic cell reprogramming in a vitamin-C-dependent manner. Cell Stem Cell 2011, 9, 575-587.

[11] Chen, J., Liu, H., Liu, J., Qi, J. et al., H3K9 methylation is a barrier during somatic cell reprogramming into iPSCs. Nat. Genet. 2013, 45, 34-42.

[12] Takahashi, T., Lord, B., Schulze, P. C., Fryer, R. M. et al., Ascorbic acid enhances differentiation of embryonic stem cells into cardiac myocytes. Circulation 2003, 107, 19121916.

[13] Keren, A., Keren-Politansky, A., Bengal, E., A p38 MAPKCREB pathway functions to pattern mesoderm in Xenopus. Dev. Biol. 2008, 322, 86-94.

[14] Tsukaguchi, H., Tokui, T., Mackenzie, B., Berger, U. V. et al., A family of mammalian $\mathrm{Na}+$-dependent L-ascorbic acid transporters. Nature 1999, 399, 70-75.

[15] Eck, P., Erichsen, H. C., Taylor, J. G., Yeager, M. et al., Comparison of the genomic structure and variation in the two human sodium-dependent vitamin $\mathrm{C}$ transporters, SLC23A1 and SLC23A2. Hum. Genet. 2004, 115, 285294.

[16] Aulehla, A., Pourquié, O. Signaling gradients during paraxial mesoderm development. Cold Spring Harb. Perspect. Biol. 2010, 2, a000869.
[17] Crescini, E., Gualandi, L., Uberti, D., Prandelli, C. et al., Ascorbic acid rescues cardiomyocyte development in Fgfr1/- murine embryonic stem cells. Biochim. Biophys. Acta. 2013, 1833, 140-147.

[18] He, X. B., Kim, M., Kim, S. Y., Yi, S. H., Rhee, Y. H. et al., Vitamin $\mathrm{C}$ facilitates dopamine neuron differentiation in fetal midbrain through TET1- and JMJD3-dependent epigenetic control manner. Stem Cells 2015, 33, 1320-32.

[19] Shin, D. M., Ahn, J. I., Lee, K. H., Lee, Y. S. et al., Ascorbic acid responsive genes during neuronal differentiation of embryonic stem cells. Neuroreport 2004, 15, 19591963.

[20] Cuaranta-Monroy, I., Simandi, Z., Kolostyak, Z., Doan-Xuan, Q. M. et al., Highly efficient differentiation of embryonic stem cells into adipocytes by ascorbic acid. Stem Cell Res 2014, $13,88-97$.

[21] Yang, S., Ding, S., Jiang, X., Sun, B. et al., Establishment and adipocyte differentiation of polycystic ovary syndromederived induced pluripotent stem cells. Cell. Prolif. 2016, 49, 352-361.

[22] Kokkinopoulos, I., Ishida, H., Saba, R., Coppen, S., Suzuki, K. et al., Cardiomyocyte differentiation from mouse embryonic stem cells using a simple and defined protocol. Dev. Dyn. 2016, 245, 157-165.

[23] Chen, J., Li, Q., Implication of retinoic acid receptor selective signaling in myogenic differentiation. Sci Rep 2016, 6, 18856.

[24] Sotiriou, S., Gispert, S., Cheng, J., Wang, Y. et al., Ascorbicacid transporter Slc23a1 is essential for vitamin C transport into the brain and for perinatal survival. Nat. Med. 2002, 8, 514-517.

[25] Gess, B., Röhr, D., Fledrich, R., Sereda, M. W. et al., Sodiumdependent vitamin $C$ transporter 2 deficiency causes hypomyelination and extracellular matrix defects in the peripheral nervous system. J. Neurosci. 2011, 31, 1718017192.

[26] Low, M., Sandoval, D., Morales, B., Nualart, F., Henríquez, J. P., Up-regulation of the vitamin $C$ transporter SVCT2 upon differentiation and depolarization of myotubes. FEBS Lett. 2011, 585, 390-396.

[27] Meredith, M. E., Harrison, F. E., May, J. M., Differential regulation of the ascorbic acid transporter SVCT2 during development and in response to ascorbic acid depletion. Biochem. Biophys. Res. Commun. 2011, 414, 737-742.

[28] Stojic, L., Jasencakova, Z., Prezioso, C., Stützer, A., Bodega, B. et al., Chromatin regulated interchange between polycomb repressive complex 2 (PRC2)-Ezh2 and PRC2-Ezh1 complexes controls myogenin activation in skeletal muscle cells. Epigenet. Chromatin 2011, 4, 1-18.

[29] Canoy, D., Wareham, N., Welch, A., Bingham, S. et al., Plasma ascorbic acid concentrations and fat distribution in 19,068 British men and women in the European Prospective Investigation into Cancer and Nutrition Norfolk cohort study. Am. J. Clin. Nutr. 2005, 82, 1203-1209.

[30] Aasheim, E. T., Hofs $\varnothing$, D., Hjelmesaeth, J., Birkeland, K. I. et al., Vitamin status in morbidly obese patients: a crosssectional study. Am. J. Clin. Nutr. 2008, 87, 362-369. 
[31] Johnston, C. S., Beezhold, B. L., Mostow, B., Swan, P. D., Plasma vitamin C is inversely related to body mass index and waist circumference but not to plasma adiponectin in nonsmoking adults. J. Nutr. 2007, 137, 17571762.

[32] Campión, J., Milagro, F. I., Fernández, D., Martínez, J. A., Diferential gene expression and adiposity reduction induced by ascorbic acid supplementation in a cafeteria model of obesity. J. Physiol. Biochem. 2006, 62, 7180 .
[33] Burr, M. L., Elwood, P. C., Hole, D. J., Hurley, R. J. et al., Plasma and leukocyte ascorbic acid levels in the elderly. Am. J. Clin. Nutr. 1974, 27, 144-151.

[34] Michels, A. J., Joisher, N., Hagen, T. M., Age-related decline of sodium-dependent ascorbic acid transport in isolated rat hepatocytes. Arch. Biochem. Biophys. 2003, 410, 112-120.

[35] Micallef, J., Attarian, S., Dubourg, O. E., Pitel, S. et al., Effect of ascorbic acid in patients with Charcot-Marie-Tooth disease type 1A: a multicentre, randomised, double-blind, placebocontrolled trial. Lancet Neurol. 2009, 8, 1103-1110. 